Vol. 9 (4): 757-762 (2019)

\title{
FOOD AND MICROBIOLOGICAL ASSESSMENT
}

\author{
Anjeza Çoku' ${ }^{1}$, Merita Xhetani ${ }^{2}$, Mirela Lika (Çekani) ${ }^{3^{*}}$ \\ ${ }^{l}$ Institute of Public Health, Tirana, Albania; \\ ${ }^{3 *}$ University of Tirana, Faculty of Natural Sciences, Department of Biology, Tirana, Albania; \\ *Corresponding Author Mirela Lika (Çekani), e-mail: mirela.lika@fshn.edu.al;
}

Received September 2019; Accepted October 2019; Published November 2019;

DOI: https://doi.org/10.31407/ijees9422

\begin{abstract}
Foods which are used from human, has been conducted on microbiological problems relating to the safety and spoilage of vegetables and fruits in recent years. Fruits and vegetables are among the richest products of vitamins, minerals and fiber. The ever-increasing demand for availability and consumption of these fresh products, along with the health aspect, has led to an increase in global fruit and vegetable trade. Contamination of fresh fruits and vegetables is a particular concern as many of these products are consumed alive without any prior processing, which would eliminate or reduce the biological, microbiological and physical hazards. Fruits and vegetables may be contaminated at any stage of growth, processing, trading, manipulation or preservation. Irregular farmers' practices are recognized as sources of microbiological contamination of vegetables. Microbiological contamination can be done directly or indirectly by water, soil, chemicals or even insects. Such a thing would necessarily lead to a potential food security problem. Over the last few years, the presence of fresh fruit and vegetables in the country's various markets and markets has increased considerably. The consumer can find and consume these products regardless of time and season. Thus, the globalization of food products as a whole not only affects the distribution of different food products but also the spread of potential risks to human health from one region to another, thus enabling wider spread of pathogens anywhere in world. As a result, increasing the level of consumption of fruits and vegetables has also become an important tool in statistics on food-borne diseases. During these years, a number of gastrointestinal diseases and poisoning have been observed, related to the consumption of fruits and vegetables contaminated with bacteria pathogens such as Listeria monocytogenes, Salmonella, Shigella sonnei and Escerichia coli 0157, present in products such as peppers, carrots, cabbage etc. Given the fact that fruits and vegetables are produced in natural environments or in greenhouses, we can say that these products are very fragile to the contamination of human pathogens. The growing level of fruit and vegetable consumption has also led to an increase in the number of poisoning to consumers.
\end{abstract}

Keywords: foods, microbiological assessment, Salmonella spp., Enterobacteriaceae. 